\title{
Potential role of systemic enzyme therapy with trypsin, bromelain and rutoside combination in burns
}

\author{
Suhas Vidyadhar Abhyankar ${ }^{1 *}$, Arvind Madhusudan Vartak ${ }^{1}$, Gautam Vinod Daftary ${ }^{2}$
}

\begin{abstract}
${ }^{1}$ Department of Burns and Plastic Surgery, Eric Kharas Memorial Burns Centre, Masina Hospital Burns, Sant Savta Marg, Byculla (East) Mumbai, Maharashtra, India

${ }^{2}$ Research and development department, Aksigen Hospital Care, Mumbai, Maharashtra, India
\end{abstract}

Received: 06 May 2021

Accepted: 04 June 2021

\section{*Correspondence:}

Dr. Suhas Vidyadhar Abhyankar,

E-mail: drsvabhyankar123@gmail.com

Copyright: (c) the author(s), publisher and licensee Medip Academy. This is an open-access article distributed under the terms of the Creative Commons Attribution Non-Commercial License, which permits unrestricted non-commercial use, distribution, and reproduction in any medium, provided the original work is properly cited.

\begin{abstract}
Burns is a global public health problem, with a higher prevalence rate in the Southeast Asia region, including India. The therapeutic interventions mainly target the control of complications following burn injury and assisting in physiological recovery. However, the excessive inflammatory changes and loss of immunological integrity, seen in burns patients, interfere with the healing process. An orally applied formulation composed of hydrolytic enzymes (bromelain, trypsin) and the flavonoid rutoside has a long history of use as natural anti-inflammatory agents. This combination has been found to exert anti-inflammatory, anti-thrombotic and antioxidant effects through myriad mechanisms that include favorable modulation of inflammatory mediators, enhancement of plasmin levels, reduced leukocyte migration to injury site and suppression of the formation of reactive oxygen species. These actions have been demonstrated in multiple in vitro and animal models. Further, the beneficial effects of the combination on inflammatory markers have been reported from multiple clinical studies. This review provides a discussion of the current understanding of cellular mechanisms and pathways involved in burn injury and the evidence highlighting the beneficial role of systemic enzyme therapy with trypsin-bromelain-rutoside combination in the management of burn injury patients.
\end{abstract}

Keywords: Hydrolytic enzymes, Proteolytic, Cytokines, Anti-inflammatory, Anti-oxidant

\section{INTRODUCTION}

\section{Epidemiology}

Burns is a global public health problem and as per World Health Organization (WHO) estimates, around 180000 deaths every year are caused by burns. The highest prevalence rates are observed in Southeast Asia region, Western Pacific region, Eastern Mediterranean region, and the lowest in the Americas. ${ }^{1}$ The low- and middle-income countries, which generally suffer from poverty, overcrowding, illiteracy, and lack of infrastructure, account for more than $90 \%$ of all mortalities and half of these occur in the Southeast Asia region. ${ }^{2,3}$ In India, over 1 million people are moderately or severely burnt every year, while the fire-related burns mortality rate is around 8.3 per 100,000 population, which is among the highest in the world. $^{3}$ Burns also have social, economic, and psychological consequences. In nonfatal cases, prolonged hospitalization, disfigurement, and disability, in addition to lost wages, emotional trauma, and erosion of family resources, contribute to the adverse impact. ${ }^{2,3}$ The Southeast Asia region is, again, the most affected, with maximum fire-related burns burden, in terms of days lost. ${ }^{3}$

\section{Management}

The tissue damage caused directly by burn injury is mostly irreversible; the therapeutic interventions mainly target subsequent complications. Current therapies involve 
stabilizing the patient, controlling infection, promoting healing, preventing further complications and assisting in physiological recovery. This is achieved by the maintenance of airway and breathing, fluid resuscitation, maintenance of adequate nutrition, wound care, topical and systemic antibiotic therapy, tetanus prophylaxis, and skin grafting. Despite improvements in the early care of burns patients, systemic inflammatory response syndrome, severe sepsis, and multiple organ dysfunction syndrome remain major causes of morbidity and mortality. ${ }^{4}$ The inflammatory processes aid wound healing by recruiting leukocytes and macrophages at the site, but excess of these interfere with the healing process. The clinical challenge is the application of therapeutic intervention only when these responses become excessive. ${ }^{5}$

There has been no breakthrough in the treatment of burns since many years now, and with the increasing resistance of bacteria to antimicrobials, the management of burns patients has become more complicated. Therapies aimed at controlling the inflammation and improving the immunological integrity have a role in treatment and can improve outcomes in such patients. ${ }^{4}$ These therapies can act as adjuvants to antimicrobials and fluid management.

Supplementation with oral hydrolytic enzymes has been reported to have analgetic, anti-edematous and antiinflammatory influences. An orally applied formulation composed of hydrolytic enzymes (bromelain, trypsin) and the flavonoid rutoside has a long history of use as natural anti-inflammatory agents. Few different formulations of this combination - dispersible tablets (Disperzyme $\left.{ }^{\circledR}\right)$, enteric-coated tablets (Phlogam $®)$, are approved for use in India. Studies in both humans and animals suggest a beneficial effect of this combination on diseases associated with inflammation and oxidative stress. These include glomerulonephritis, allergic encephalomyelitis and allograft arteriosclerosis, in rats, metabolic syndrome in rabbits, and clinical studies in post-surgical inflammation, acute thrombophlebitis, osteoarthritis, pediatric sepsis, ankle sprain and other rheumatic diseases. ${ }^{6-18}$

This review provides a discussion of the current understanding of cellular mechanisms and pathways involved in burn injury and the evidence describing the potential role of systemic enzyme therapy with trypsinbromelain-rutoside combination in the management of burn injury patients.

\section{Pathophysiology of systemic effects of burns}

The release of cytokines and other inflammatory mediators at the site of injury has a systemic effect once the burn reaches $30 \%$ of total body surface area. ${ }^{19}$ The systemic pathophysiology of the burn wound involves an inflammatory reaction leading to rapid edema formation because of increased microvascular permeability accompanied by vasodilation and increased extravascular osmotic activity. ${ }^{20}$ The mechanisms involved in microvascular dysfunction mainly include thrombosis of vessels due to vascular damage, upregulation of inflammatory mediators, and proapoptotic factors. Microvascular injury is mediated by inflammatory mediators such as histamine, bradykinin, prostaglandins, leukotrienes, vasoactive amines, platelet activation products and complement. ${ }^{21}$ The transcription activator protein, Nuclear factor $\kappa \mathrm{B}(\mathrm{NF}-\kappa \mathrm{B})$, is activated by burn injury and is believed to regulate the induction of several inflammatory mediators, including tumor necrosis factor alpha (TNF- $\alpha)$. Another source of proinflammatory mediators, that cause microvascular damage, are the leukocytes sequestered at the injury site. ${ }^{22}$ Lipid peroxidation, leading to generation of reactive oxygen species, plays a critical role in burn-induced plasma leakage by contributing to the increased microvascular permeability, edema formation, and tissue damage after burn injury. ${ }^{20}$ Further, bradykinin, which is produced at the burn injury site, acts as a powerful vasoactive mediator that causes venular dilation, increased microvascular permeability, smooth muscle contraction, and pain. ${ }^{22}$

A biphasic response has been identified as a result of the mediators released by tissue injury. In the first phase referred to as systemic inflammatory response syndrome (SIRS), macrophages play a central role. They are major producers of proinflammatory mediators (like prostaglandin E2, reactive nitrogen intermediates, interleukin (IL)-6, TNF- $\alpha$ ) and thermal injury increases the production of these mediators by macrophages. These inflammatory mediators coupled with increase of vascular hydrostatic pressure caused by vessel dilation are the major reasons for systemic microvascular leakage observed in burns. ${ }^{22}$ The result is a fall in intravascular colloid osmotic pressure and the escape of fluid, electrolytes and proteins from the vascular system, with rapid equilibration with the interstitial compartments. This manifests as hypovolemia, hemoconcentration, oedema, reduced urine output and cardiovascular dysfunction. ${ }^{22}$ As a response to inflammation, the endothelial cell junctions widen and gaps form, resulting in compromised barrier functions. ${ }^{22}$ In severe burns patients, coagulopathy is frequently observed and is characterized by procoagulant and antifibrinolytic changes, together with impaired activity of the natural anticoagulant systems. ${ }^{23}$ The release of acute-phase proteins such as $\alpha 1$ antitrypsin and $\alpha 2$ macroglobulin by the liver, which bind to plasmin, are believed to cause shut down of fibrinolysis. The occurrence of coagulopathy in patients with severe burns is associated with increased morbidity, including thromboembolic complications and multiple organ failure, and increased mortality. ${ }^{23}$

This is followed by a prolonged and profound hypermetabolic phase, especially in patients with larger burns, that involves increased production of proinflammatory cytokines, as well as the formation of reactive oxygen species (ROS). These include superoxide anion, hydroxyl radical, hydrogen peroxide, and reactive nitrogen species, such as nitric oxide (NO) and peroxynitrite. Apoptosis is induced in various cell 
elements, partly due to the action of TNF- $\alpha$. Other proapoptotic factors that show increased expression include Bax, Bcl-xl, and caspase-3.22 The hypermetabolism and associated chronic inflammation and lean body mass wasting can impair wound healing. The immune status alterations associated with the condition increases the susceptibility to infection via the burn wound, further exacerbating systemic inflammation. ${ }^{20,5}$ The free radicals have been found to have beneficial effects on antimicrobial action and wound healing. However, the enormous production of ROS, that follows a burn injury, often ends up being harmful and is implicated in inflammation, SIRS, immunosuppression, infection and sepsis, tissue damage, and multiple organ failure. Thus, the balance between production of free radicals and their detoxification, is key to clinical progress in burns patients. ${ }^{22}$

\section{PHARMACODYNAMICS OF BROMELAIN, TRYPSIN AND RUTOSIDE}

\section{Pharmacodynamics of Bromelain}

Bromelain is a family of proteolytic enzymes obtained from the pineapple plant. Bromelain has fibrinolytic, antithrombotic, and anti-inflammatory properties, all of which can help in controlling the complications of burns. ${ }^{24}$ Significant amount of bromelain, in its intact and biologically active form, has been found to reach plasma after oral ingestion. ${ }^{25}$

Bromelain stimulates the conversion of plasminogen to plasmin, resulting in increased fibrinolysis. ${ }^{26}$ In animal experiments, oral and parenteral administration of Bromelain led to significant increases in the prothrombin time and antithrombin time, with elevation of serum plasmin levels and serum fibrinolytic activity (SFA) in a dose-dependent fashion. ${ }^{24}$ The fibrinolytic activity is accompanied by its inhibitory effect on ADP-induced platelet aggregation. Bromelain prevents thrombininduced human platelet aggregation and reduces the adhesion of bound, thrombin-stimulated platelets to endothelial cells. ${ }^{27}$

Bromelain has been reported to lower kininogen and bradykinin levels, respectively, in serum by up to $60 \%$ along with symptoms of inflammation. ${ }^{24}$ This has been confirmed in rats and in vitro studies. ${ }^{28,29}$ It has also been shown to cause dose-dependent decrease of prostaglandin E2 levels and thromboxane B2 levels in experimentally induced inflammations. ${ }^{24}$ The Phospholipase A2 (Pla2) inhibitory potential and reduction of both PGE2 and substance $\mathrm{P}$ has been demonstrated in in vitro, in vivo and in silico studies. ${ }^{30,31}$

Another important action of bromelain is the reduction in IL-8 induced migration of leukocytes to the site of inflammation. This has been demonstrated using in vitro chemotaxis assay and in murine in vivo models. ${ }^{32}$ This action is primarily exerted through the alteration of cell surface molecules that are involved in leukocyte homing and cellular adhesion and activation. ${ }^{33}$ By achieving this, bromelain can control the subsequent release of proteases (mainly from neutrophils) and pro-inflammatory cytokines (by the macrophages), which constitute an important part of the inflammatory process.

Bromelain can also benefit burns management, indirectly, by improving the absorption and tissue permeability of antibiotic drugs. This action has been reported with amoxycillin and tetracycline after subcutaneous and intramuscular application of the antibiotics. The higher serum and tissue levels attained were also associated with lesser side effects. ${ }^{34}$

\section{Pharmacodynamics of Trypsin}

Trypsin is a serine protease of animal origin, which specifically hydrolyze peptides containing lysine and arginine. Around $10 \%$ of an orally administered trypsin dose ends up in the blood. ${ }^{35}$ Trypsin has been found to have the following effects, which can help in the management of burns - enhanced fibrinolysis, enhanced wound-healing and lowering of proinflammatory cytokines.

Trypsin circulates in blood stream bound to alpha-1 antitrypsin ( $\alpha 1-\mathrm{AT})$ and has more affinity to it than plasmin, allowing more plasmin to be available for fibrinolysis. Studies with trypsin in rabbits and dogs have reported diminution and/or disappearance of the thrombus in situ, restoration of local circulation, and restoration of vessel wall compressibility. ${ }^{36}$ In vitro studies have demonstrated that exposure of fibrinogen to trypsin immediately impaired its clottability by thrombin. ${ }^{37}$

It has been demonstrated to promote differentiation of fibrocytes to a more healing/repairing profile. When peripheral blood mononuclear cells (PBMC) and monocytes were isolated, cultured and incubated with trypsin for 5 days in a defined serum-free medium, it potentiated the differentiation of human monocytes to fibrocytes in cell culture. Adding trypsin inhibitors increased the amount of trypsin needed to potentiate fibrocyte differentiation, suggesting that the potentiating effect is dependent on trypsin proteolytic activity. ${ }^{38}$ The change in fibrocyte profile was demonstrated when PBMC were isolated and cultured to differentiate fibrocytes and macrophages in serum-free media to polarize macrophages towards M1 and M2 phenotypes for a week followed by treatment with trypsin for 2 days. Trypsin appeared to act as through G-protein-coupled protease-activated receptors (PARs), specifically PAR1 and PAR2 receptors, altering macrophage surface marker expression and the macrophage secretion profile towards an M2a phenotype. M2a macrophages are involved in wound healing and fibrosis. ${ }^{39}$

\section{Pharmacodynamics of Rutoside}

Rutoside, polyphenolic bioflavonoid, is extracted from natural sources such as oranges, lemons, grapes, limes, 
berries, and peaches. It has demonstrated several pharmacological activities in many studies, including antioxidant, cytoprotective, vasoprotective, anticarcinogenic, neuroprotective and cardioprotective activities. $^{40}$

The chelating and free radical scavenging activity of rutin has been extensively studied. Rutin has been found to suppress the formation of superoxide ion, the generation of hydroxyl radicals and the formation of lipid peroxy radicals. ${ }^{41}$ It has also been demonstrated to inhibit the transcription of more than 20 genes encoding critical proinflammatory factors, including TNF- $\alpha$, IL-1, IL-8, TNF- $\alpha$, macrophage migration inhibitory factor (MIF), and chemotactic factors in human activated macrophages. ${ }^{42}$ Consequent to this, decrease in the concentration of IL- $1 \beta$, TNF- $\alpha$, and IL- 6 was observed. The production of inducible nitric oxide synthase (iNOS)mediated NO by human macrophages was also decreased in a dose-dependent manner. ${ }^{42}$ The anti-inflammatory and antioxidant effects have been confirmed in multiple murine models of inflammation. ${ }^{42-44}$

Rutin, in a dose-dependent manner, has also been found to attenuate the vascular permeability increase due to histamine, bradykinin and fibrin degradation products. ${ }^{45,46}$ It also inhibits human platelet aggregation stimulated by agonists like collagen in a concentration-dependent manner. It markedly inhibited intracellular calcium mobilization and thromboxane A2 formation in human and rabbit platelets stimulated by collagen and platelet activating factor (PAF), respectively. ${ }^{47,48}$

\section{POTENTIAL OF THE COMBINATION IN BURNS}

The proteolytic enzymes, trypsin and bromelain, help in mitigating excessive inflammatory reactions and resulting impairment of the natural defense mechanism. Fibrin deposits get absorbed with restitution of impaired microcirculation. The reduction in prostaglandins and products like substance $\mathrm{P}$ also help in controlling the pain associated with inflammation. The enzymes can also help in overcoming the infections by enhancing the absorption and tissue penetration of antimicrobial drugs. The flavonoid rutoside further boosts the reduction of inflammation and platelet aggregation, and also exerts action through its inhibition of microsomal lipid peroxidation and potent hydroxyl radical scavenging action.

\section{Evidence in burns}

In a rat model of electrical burn injury, intraperitoneal administration of bromelain was able to inhibit the increase in NO, a marker for vascular inflammation and matrix metalloprotease (MMP)-9, an enzyme pivotal to the remodeling of the extracellular matrix. ${ }^{49}$ Rutoside, when administered intravenously over two doses, to dogs with $15 \%$ total body surface area third-degree flame burn, reduced the continuing plasma volume loss. The two doses of rutoside were also able to show trends towards improved cardiac output. ${ }^{50}$ Trypsin, with chymotrypsin, when administered orally to 15 burn patients, led to a significant decrease in IL-1 $\beta$ and IL-6 levels by day $7 .{ }^{51} \mathrm{In}$ another study of 30 burn patients with $20-30 \%$ deep second-degree burns, the same combination demonstrated reduction in the levels of $\mathrm{C}$-reactive protein by day 7 , with increase in the levels of $\alpha 1$-antitrypsin and $\alpha 2$ macroglobulin, suggesting potent anti-inflammatory action. ${ }^{52}$ The enzyme combination, led to decreased formation of lipid peroxidation products, indicating reduced tissue destruction along with marked reduction in the levels of liver enzymes - transaminases, creatine phosphokinase (CPK), alkaline phosphatase (ALP), and lysosomal enzymes - neutrophil elastase and cathepsin D, indicating its potential to reduce stress to the liver and limiting the damage to tissues. ${ }^{53,54}$

\section{CONCLUSION}

Despite improvements seen in burn care over the last several years, burn injury is still a clinical challenge and continues to be a global public health problem. With improved survival, the focus of care has shifted to optimizing recovery and rehabilitation. Trypsin, bromelain and rutoside can be beneficial in the management of burns based on the myriad actions of the individual ingredients, including reduction of mediators of inflammations and pain, acceleration of fibrinolysis, inhibition of platelet aggregation, enhanced healing, and antioxidant activity. The impact of the individual ingredients has been evidenced in either animal models or clinical studies. Based on this, it has been hypothesized that when combined, they can positively impact the clinical outcome in burns. We, further, intend to test this hypothesis in controlled study(ies) in burns patients.

\section{Funding: No funding sources}

Conflict of interest: Gautam Daftary is the chairman of Aksigen Hospital Care, Mumbai, which markets a few brands of the combination of trypsin, bromelain and rutoside in India.

Ethical approval: Not required

\section{REFERENCES}

1. Burns. WHO, 2018. http://www.who.int/ mediacentre/factsheets/fs365/en/. Accessed on April $1,2021$.

2. Burns. WHO. http://www.who.int/violence_injury _prevention/other_injury/burns/en/. Accessed on April 1, 2021.

3. Atiyeh B, Masellis A, Conte C. Optimizing Burn Treatment in Developing Low- and Middle-Income Countries with Limited Health Care Resources (Part 1). Ann Burns Fire Disasters. 2009;22(3):121-5.

4. Church D, Elsayed S, Reid O, Winston B, Lindsay R. Burn Wound Infections. Clin Microbiol Rev. 2006;19(2):403-34. 
5. Rowan M, Cancio L, Elster E, Burmeister D, Rose L, Natesan $\mathrm{S}$ et al. Burn wound healing and treatment: review and advancements. Critical Care. 2015;19(1):1-12.

6. White R, Lowrie L, Stork J, Iskandar S, Lamm M, Emancipator S. Targeted enzyme therapy of experimental glomerulonephritis in rats. Journal of Clinical Investigation. 1991;87(5):1819-27.

7. Targoni O, Tary-Lehmann M, Lehmann P. Prevention of Murine EAE by Oral Hydrolytic Enzyme Treatment. J Autoimmun. 1999;12(3):1918.

8. Gaciong Z, Paczek L, Bojakowski K, Socha K, Wisniewski M, Heidland A. Beneficial effect of proteases on allograft arteriosclerosis in a rat aortic model. Nephrology Dialysis Transplantation. 1996;11(6):987-89.

9. Talaieva T, Bratus V. Proteolytic Enzyme Combination Reduces Inflammation and Oxidative Stress and Improves Insulin Sensitivity in a Model of Metabolic Syndrome. Adv Enzyme Res. 2015;03(01):1-8.

10. Nanda M, Kaur M. Role of Oral Enzymes in Post Operative Septoplasty Cases. Indian Journal of Otolaryngology and Head \& Neck Surgery. 2014;71(S3):1663-67.

11. Forrest W, Goodridge D, MacDonald Watson A, Starkey W. Double-blind clinical trials of proteolytic enzyme therapy in oral surgery. British Journal of Oral Surgery. 1968;6(1):7-10.

12. Kamenícek V, Holán P, Franěk P. Systemic enzyme therapy in the treatment and prevention of posttraumatic and postoperative swelling. Acta Chir Orthop Traumatol Cech. 2001;68(1):45-9

13. Singh T, More V, Fatima U, Karpe T, Aleem M, Prameela J. Effect of proteolytic enzyme bromelain on pain and swelling after removal of third molars. Journal of International Society of Preventive and Community Dentistry. 2016;6(9):197.

14. Baumueller M, Rau S. Efficacy and tolerance of systemic enzyme therapy in the treatment of acute thrombophlebitis-a randomised double-blind controlled trial. Journal Phlebology and Lymphology. 2018;11(1).

15. Ueberall M, Mueller-Schwefe G, Wigand R, Essner U. Efficacy, tolerability, and safety of an oral enzyme combination vs diclofenac in osteoarthritis of the knee: results of an individual patient-level pooled reanalysis of data from six randomized controlled trials. J Pain Res. 2016;9:941-61.

16. Shahid S, Turakhia N, Kundra M, Shanbag P, Daftary G, Schiess W. Efficacy and Safety of Phlogenzym--A Protease Formulation, in Sepsis in Children. JAPI. 2002;50:527-31.

17. Kerkhoffs G, Struijs P, Wit C, Rahlfs V, Zwipp H, Van Dijk C. A double blind, randomised, parallel group study on the efficacy and safety of treating acute lateral ankle sprain with oral hydrolytic enzymes. Br J Sports Med. 2004;38(4):431-35.
18. Wittenborg A, Bock P, Hanisch J, Saller R, Schneider B. Comparative epidemiological study in patients with rheumatic diseases illustrated in an example of a treatment with non-steroidal anti-inflammatory drugs versus an oral enzyme combination. Arzneimittel Forschung/Drug Research. 2000;50(8):728-38.

19. Hettiaratchy S, Dziewulski P. ABC of burns Pathophysiology and types of burns. BMJ. 2004;328(7453):1427-29.

20. Arturson G. Pathophysiology of the burn wound and pharmacological treatment. The Rudi Hermans Lecture, 1995. Burns. 1996;22(4):255-74.

21. Snell J, Loh N, Mahambrey T, Shokrollahi K. Clinical review: The critical care management of the burn patient. Critical Care. 2013;17(5):241.

22. Nielson C, Duethman N, Howard J, Moncure M, Wood J. Burns. Journal of Burn Care \& Research. 2017;38(1):e469-81.

23. Glas G, Levi M, Schultz M. Coagulopathy and its management in patients with severe burns. Journal of Thrombosis and Haemostasis. 2016;14(5):865-74.

24. Lotz-Winter H. On the Pharmacology of Bromelain: An Update with Special Regard to Animal Studies on Dose-Dependent Effects. Planta Med. 1990;56(03):249-53.

25. Castell J, Friedrich G, Kuhn C, Poppe G. Intestinal absorption of undegraded proteins in men: presence of bromelain in plasma after oral intake. American Journal of Physiology-Gastrointestinal and Liver Physiology. 1997;273(1):G139-46.

26. Bromelain Monograph. Alternative Medicine Review. 2010;15(4):361-68.

27. Metzig C, Grabowska E, Eckert K, Rehse K, Maurer H. Bromelain proteases reduce human platelet aggregation in vitro, adhesion to bovine endothelial cells and thrombus formation in rat vessels in vivo. In Vivo (Brooklyn). 1999;13(1):7-12.

28. Oh-ishi S, Uchida Y, Ueno A, Katori M. Bromelain, a thilprotease from pineapple stem, depletes high molecular weight kininogen by activation of Hageman factor (factor XII). Thromb Res. 1979;14(4-5):665-72.

29. SUDA H, YAMAUCHI H, ISO T. Potentiative effect of angiotensin converting enzyme inhibitor on carrageenan edema in rats and the role of tissue kininogen. J Pharmacobio-dyn 1984;7(6):372-77.

30. Gaspani L, Limiroli E, Ferrario P, Bianchi M. In vivo and in vitro Effects of Bromelain on PGE and SP Concentrations in the Inflammatory Exudate in Rats. Pharmacology. 2002;65(2):83-86.

31. Mohamed Tap F, Abd Majid F, Ismail H, Wong T, Shameli K, Miyake M et al. In Silico and In Vitro Study of the Bromelain-Phytochemical Complex Inhibition of Phospholipase A2 (Pla2). Molecules 2018;23(1):73.

32. Fitzhugh D, Shan S, Dewhirst M, Hale L. Bromelain treatment decreases neutrophil migration to sites of inflammation. Clinical Immunology. 2008;128(1):66-74. 
33. Hale L, Greer P, Sempowski G. Bromelain Treatment Alters Leukocyte Expression of Cell Surface Molecules Involved in Cellular Adhesion and Activation. Clinical Immunology. 2002;104(2):183-90.

34. Maurer H. Bromelain: biochemistry, pharmacology and medical use. Cellular and Molecular Life Sciences. 2001;58(9):1234-45.

35. Lehmann P. Immunomodulation by proteolytic enzymes. Nephrology Dialysis Transplantation. 1996;11(6):953-55.

36. Innerfield I, Schwarz A, Angrist A. intravenous trypsin: its anticoagulant, fibrinolytic and thrombolytic effects. Journal of Clinical Investigation. 1952;31(12):1049-55.

37. Alexander B, Pechet L, Kliman A. Proteolysis, Fibrinolysis, and Coagulation: Significance in Thrombolytic Therapy. Circulation. 1962;26(4):596611.

38. White M, Glenn M, Gomer R. Trypsin Potentiates Human Fibrocyte Differentiation. PLoS One. 2013;8(8):e70795.

39. White M, Gomer R. Trypsin, Tryptase, and Thrombin Polarize Macrophages towards a ProFibrotic M2a Phenotype. PLoS One. 2015;10(9):e0138748.

40. Ganeshpurkar A, Saluja A. The Pharmacological Potential of Rutin. Saudi Pharmaceutical Journal. 2017;25(2):149-64.

41. Afanas'ev I, Dcrozhko A, Brodskii A, Kostyuk V, Potapovitch A. Chelating and free radical scavenging mechanisms of inhibitory action of rutin and quercetin in lipid peroxidation. Biochem Pharmacol. 1989;38(11):1763-69.

42. Kauss T, Moynet D, Rambert J, Al-Kharrat A, Brajot $\mathrm{S}$, Thiolat $\mathrm{D}$ et al. Rutoside decreases human macrophage-derived inflammatory mediators and improves clinical signs in adjuvant-induced arthritis. Arthritis Res Ther. 2008;10(1):R19.

43. Adefegha S, Leal D, de Oliveira J, Manzoni A, Bremm J. Modulation of reactive oxygen species production, apoptosis and cell cycle in pleural exudate cells of carrageenan-induced acute inflammation in rats by rutin. Food Funct. 2017;8(12):4459-68.

44. Khajevand-Khazaei M, Mohseni-Moghaddam P, Hosseini M, Gholami L, Baluchnejadmojarad T, Roghani M. Rutin, a quercetin glycoside, alleviates acute endotoxemic kidney injury in C57BL/6 mice via suppression of inflammation and up-regulation of antioxidants and SIRT1. Eur J Pharmacol. 2018;833:307-13.
45. Gerdin B, Svensjö E. Inhibitory effect of the flavonoid O-(beta-hydroxyethyl)-rutoside on increased microvascular permeability induced by various agents in rat skin. Int J Microcirc Clin Exp. 1983;2(1):39-46.

46. Blumberg S, Clough G, Michel C. Effects of hydroxyethyl rutosides upon the permeability of single capillaries in the frog mesentery. $\mathrm{Br} \mathrm{J}$ Pharmacol. 1989;96(4):913-19.

47. Sheu J, Hsiao G, Chou P, Shen M, Chou D. Mechanisms Involved in the Antiplatelet Activity of Rutin, a Glycoside of the Flavonol Quercetin, in Human Platelets. J Agric Food Chem. 2004;52(14):4414-18.

48. Chen W, Jin M, Wu W. Experimental study on inhibitory effect of rutin against platelet activation induced by platelet activating factor in rabbits. Zhongguo Zhong $\mathrm{Xi}$ Yi Jie $\mathrm{He}$ Za Zhi. 2002;22(4):283-85.

49. Maluegha D, Widodo M, Pardjianto B, Widjajanto E. The effects of bromelain on angiogenesis, nitric oxide, and matrix metalloproteinase- 3 and -9 in rats exposed to electrical burn injury. Wound Medicine. 2015;9:5-9.

50. Hilton J. Effects of $\beta$-hydroxyethyl rutosides (H-R) administered post burn after thermal-injury-induced plasma volume loss in the nonresuscitated dog. Burns. 1982;8(6):391-94.

51. RaviKumar T, Ramakrishnan M, Jayaraman V, Babu M. Effect of trypsin-chymotrypsin (Chymoral Forte D.S.) preparation on the modulation of cytokine levels in burn patients. Burns. 2001;27(7):709-16.

52. Latha B, Ramakrishnan K, Jayaraman V, Babu M. Action of trypsin : chymotrypsin (Chymoral forte DS) preparation on acute-phase proteins following burn injury in humans. Burns. 1997;23:S3-S7.

53. Latha B, Ramakrishnan M, Jayaraman V, Babu M. The efficacy of Trypsin: Chymotrypsin preparation in the reduction of oxidative damage during burn injury. Burns. 1998;24(6):532-38.

54. Latha B, Ramakrishnan M, Jayaraman V, Babu M. Serum enzymatic changes modulated using trypsin: chymotrypsin preparation during burn wounds in humans. Burns. 1997;23(7-8):560-64.

Cite this article as: Abhyankar SV, Vartak AM, Daftary GV. Potential role of systemic enzyme therapy with trypsin, bromelain and rutoside combination in burns. Int Surg J 2021;8:2254-9. 